\title{
Health and school performance of teenagers born before 29 weeks gestation
}

\author{
A Johnson, U Bowler, P Yudkin, C Hockley, U Wariyar, F Gardner, L Mutch
}

Arch Dis Child Fetal Neonatal Ed 2003;88:F190-F198

\begin{abstract}
Objective: To ascertain the health and school performance of teenagers born before 29 weeks gestation (extremely low gestational age (ELGA)) and to compare those in mainstream school with classroom controls.

Methods: Three geographically defined cohorts of babies born in 1983 and 1984 were traced at the age of 15-16 years. Their health, abilities, and educational performance were ascertained using postal questionnaires to the teenagers themselves, their parents, their general practitioners, and the teachers of those in mainstream school. Identical questionnaires were sent to classroom controls. Results: Of the 218 teenagers surviving to the age of 16 years, information was obtained on 179 . Of these, 29 were in special schools and 150 in mainstream school, 10 of whom had severe motor or sensory impairment. Using the Child Health Questionnaire, parents of teenagers in mainstream school reported a higher incidence of problems than controls in physical functioning (difference in mean scores 9.0 (95\% confidence interval (CI) 4.9 to 13.1)) and family life (difference in mean scores for family cohesion $7.0(95 \% \mathrm{Cl} 1.6$ to 12.4$))$. In all areas of learning, teachers rated the ability of the ELGA teenagers in mainstream school lower than the control group. Parents of teenagers in special schools reported a higher rate of problems in most areas.

Conclusions: One in six ELGA survivors at age 16 years have severe disabilities and are in special schools. Most ELGA survivors are in mainstream school and are coping well as they enter adult life, although some will continue to need additional health, educational, and social services.
\end{abstract}

See end of article for authors' affiliations

t is well known that babies born at extremely low gestational age (ELGA) are at risk of motor and sensory impairment, ${ }^{12}$ specific learning difficulties at school, ${ }^{3-7}$ and behavioural problems. ${ }^{8-11}$ Although a number of children with severe motor, sensory, and intellectual difficulty will be in special schools or in special units, most of these preterm survivors are in a mainstream school. Little is known, however, of how these children fare in later school years and as they approach school leaving. It is not known how motor and sensory deficits, growth delay, or other physical impairments may evolve and influence the adolescents' views of their overall level of health and abilities, and how they will function in the adult world.

In 1983-1984, three cohorts of babies born before 29 weeks gestation in three different parts of the United Kingdom were identified, and the survivors were followed up at different ages. ${ }^{79^{12-15}}$ The total number of liveborn babies in the three cohorts was 535, and 218 were thought to be alive at the age of 16 years. It was decided to develop a collaborative study to ascertain their outcome compared with a group of peers, as they reached the end of their years at school and embarked on adulthood. Information on the outcome of cohorts, defined by gestational age at birth rather than birth weight, is needed by obstetricians and parents to make informed decisions before and around the time of birth. The collaboration provided relatively large numbers, making it possible to get more precise estimates of the risks of later adverse outcomes in this group of children than would have been possible with a study based on a single area.

We were particularly concerned to get an overall picture of how the surviving teenagers fare in every day life, how they view themselves, and how their health and abilities are perceived by parents and teachers. Drawing on detailed standardised instruments, we developed a series of questionnaires to be completed by the teenagers, their parents, general practitioners, and teachers. In this paper, we describe the whole cohort in these terms. We also wished to compare the outcome of this group with a control group of teenagers of higher gestational age. As it is not possible to select appropriate controls for children in special schools, we have confined the comparison to children who are in mainstream school. We hypothesised that there is a higher rate of continuing health problems, both physical and psychological, and low educational performance among 15-16 year old children in mainstream school who were born before 29 weeks of gestation compared with classroom controls of higher gestational age.

\section{METHODS}

The original three cohorts were all defined by maternal residence at the time of birth. They were all babies born before 29 weeks gestation in 1983 in the former Northern Region and in 1984 in Scotland and in the former Oxford Region. Gestational age had been checked at the time of assembly of the cohorts using a combination of menstrual dates and ultrasound before 20 weeks when available. The scan date was preferred if the menstrual date was uncertain and if there was a discrepancy of more than 14 days between the menstrual date and scan estimate. Three local coordinators ran this project, one in Newcastle, one in Glasgow, and one in Oxford who had overall coordinating responsibility.

Surviving children in the three cohorts had been reassessed at different ages in preschool and early school years. The name and address of the child's general practitioner at the time of the most recent assessment was traced, and a letter sent asking if the child was still registered with the practice. If so, the general practitioner was asked if it was thought appropriate for the family to be approached. If the child was no longer registered with that general practitioner, the NHS Central Register was asked to confirm that the child was still alive, and, if so, to provide the location of the child's current general practitioner. 
Once located, and with the general practitioner's permission, the research coordinator for that area contacted the family by letter. Written permission was requested from both the parents and teenagers to send a questionnaire to each of them and to the teenager's teacher and general practitioner. This initial contact differed in the three areas. In the Northern region, the initial letter was followed by a telephone call requesting a visit to the teenager's home as part of the protocol for another study. The visit was planned to take place after the questionnaires had been completed. In the Oxford area, the initial letter was addressed to the parents asking them to pass a consent form to their teenager. In Scotland, to conform with Scots law, the initial letter was sent directly to the teenager asking for permission to approach firstly their parents and then their teacher and general practitioner.

If the parents and teenager gave their permission for the school to be approached, a letter was sent to the head teacher enclosing a questionnaire for the year tutor of the teenager. The head teacher was also asked to help to identify controls by letting us have the names and addresses of three teenagers in the same year group matched by sex and nearest in birth date to the ELGA teenager. As we aimed to have one control for each ELGA teenager, initially we approached the first of the control families. If the family did not respond or did not wish to participate, we then approached the second, and if necessary the third. This proved to be a slow process, and, in addition, some schools were reluctant to release names and addresses of possible control families. Early in the study therefore we decided to ask the head teacher to give the letters directly to up to three control teenagers. There was a variable level of compliance both within the schools and the families, and we have no knowledge of the characteristics of the potential controls who failed to respond. Finally, a questionnaire was sent to the general practitioner of both the ELGA teenagers and the controls, provided that they had given consent.

In two of the three geographic areas of the study, questionnaires from all respondents were returned to the local coordinators. Two reminders were sent to non-responders, and telephone contact was made where that was possible; missing data from returned questionnaires were followed up in the same way. In the Northern region, the questionnaires completed by parents and teenagers were retrieved at the time of a visit to the family by a developmental paediatrician. All completed questionnaires were sent to the coordinating office in Oxford.

The project was approved by the Oxford multi-centre research ethics committee and by the local ethics committees in each area.

\section{Questionnaires}

There were three questionnaires concerning all the teenagers in the study, which were completed by the teenager, parent, and general practitioner. In addition, questionnaires were sent to the teachers of teenagers in mainstream school, asking them to compare their school performance with others in the same class. Questionnaires are available on request.

The teenager questionnaire included questions about family structure and relationships, and items from the Health Education Authority questionnaire on health and perceptions of fitness, exercise, smoking, and drug use. ${ }^{16}$ Further questions were asked about onset of puberty, attitudes to school, bullying, and aspirations for the future.

The parent questionnaire included questions on the parents' work situation and educational status. Social class was based on male partner's occupation or, if this was not available, on the mother's occupation. ${ }^{17}$ Parents' views of their teenager's health and daily activities, and the impact of their teenager's health and behaviour on themselves and the family were explored using questions from the child health questionnaire. ${ }^{18}$ The responses to the questions can be summarised in standardised scores (maximum score $=100$; high scores represent "better" health) for global health, physical functioning, limitations because of physical health, time impact on parent, overall family activities, and family cohesion. Where parents reported that their child had been seen by specialist services, we asked their permission to approach these services for further information.

In a short questionnaire, teachers were asked about learning support for the teenager and to rate the teenager's ability in a number of academic and other areas. This was done by indicating the teenager's ability, compared with a class of mixed ability, on a visual analogue scale. The scale was from 0-30 with 0-3 rated as poor, 4-9 as below average, 10-21 as average, $22-27$ as above average, and 28-30 as excellent. This approach was used in the Scottish low birthweight study, and scores correlated well with standardised tests administered concurrently (L Mutch, unpublished work). In the Northern and Oxford cohorts, the results of Standard Assessment Tasks administered at age 14 years (SATS, Key Stage 3) were requested with prior permission from parents and teenagers. In Scotland, the results of Standard Grade assessments were classed according to the level at which the students were to be presented: credit equivalent to grades 1 and 2 GCSE, general level (grades 3 and 4), and foundation (grades 5 and 6). More able children were presented for biology, chemistry, and physics separately, whereas others did a general science exam. No earlier public exam results are available.

The short questionnaire to general practitioners contained questions about overall health, use of medication, and admission to hospital in the last six years.

\section{Sample size}

We estimated that 170 ELGA children in mainstream schools would take part, with 170 controls. Given a prevalence rate of $10 \%$ in any adverse outcome in the controls, this sample size would have enabled us to detect $(2 \alpha=0.05 ; \beta=0.20)$ an increase in prevalence to $21 \%$ in the ELGA children. In fact, the smaller numbers of controls enrolled enabled detection of a prevalence rate of $24 \%$ in the ELGA children.

\section{Statistical analysis}

Comparisons between proportions were made using exact tests. Comparisons between means were made using the $t$ test (with the Welch test for unequal variances). The software used was SPSS version 9 and StatXact 3 (Cytel Software Corporation, Cambridge, Massachusetts, USA).

\section{RESULTS}

Of the 535 babies in the original cohorts, 218 were alive at age 16 years. Of these, at least one completed questionnaire was available for 179 (82\%) of the ELGA teenagers. Three teenagers had emigrated, and contact was refused by the general practitioner for five families. Five families who were successfully contacted refused to participate, and there was no response from 26. Non-responders were comparable to responders in birth weight and gestational age, but were of lower social class (table 1). Of the 179 ELGA teenagers for whom some information was available, 150 were in a mainstream school at the time of assessment and 29 were in a special school; 108 teenagers agreed to participate as controls.

Of the 29 in special schools, 11 had cerebral palsy, six of whom had no independent walking. Four of these also had low vision and severe learning difficulties and were totally dependent. Five further teenagers were blind; two of these had severe learning difficulties. Two were profoundly deaf, and the remaining 11 had severe learning and/or behavioural difficulties. In addition, 10 teenagers in mainstream school had a severe level of motor or sensory disability. Four had cerebral palsy and no independent walking; two further teenagers with cerebral palsy were severely restricted in motor function 
Table 1 Characteristics of ELGA teenagers who were responders and non-responders

\begin{tabular}{|c|c|c|c|}
\hline & $\begin{array}{l}\text { Responders } \\
(n=179)\end{array}$ & $\begin{array}{l}\text { Non-responders } \\
(n=39)\end{array}$ & p Value \\
\hline \multicolumn{4}{|l|}{ Birth weight $(\mathrm{g})$} \\
\hline Mean (SD) & 1048 (209) & 1051 (229) & \\
\hline$<750$ & $9(5)$ & $1(3)$ & 0.46 \\
\hline $750-999$ & $65(36)$ & $18(46)$ & \\
\hline$\geqslant 1000$ & $105(59)$ & $20(51)$ & \\
\hline \multicolumn{4}{|l|}{ Gestational age (weeks) } \\
\hline Mean (SD) & $27.1(1.1)$ & $26.9(1.1)$ & \\
\hline 26 or less & $48(27)$ & $13(33)$ & 0.46 \\
\hline 27 & 47 (26) & $12(31)$ & \\
\hline 28 & 84 (47) & $14(36)$ & \\
\hline \multicolumn{4}{|l|}{ Sex } \\
\hline Male & 85 (47) & $20(51)$ & 0.80 \\
\hline Female & $94(53)$ & 19 (49) & \\
\hline \multicolumn{4}{|l|}{ Area of residence } \\
\hline Northern region & $57(32)$ & $1(3)$ & $<0.001$ \\
\hline Scotland & $80(45)$ & $24(62)$ & \\
\hline Oxford & 42 (23) & $14(36)$ & \\
\hline Social Class when last seen (Oxford and Scotland only) & $n=122$ & $\mathrm{n}=38$ & \\
\hline Professional/semiprofessional & $29(24)$ & $5(13)$ & 0.021 \\
\hline Skilled & $46(38)$ & $7(18)$ & \\
\hline Semiskilled/unskilled & $15(12)$ & $11(29)$ & \\
\hline Armed forces & $6(5)$ & $3(8)$ & \\
\hline No paid employment & $26(21)$ & $12(32)$ & \\
\hline $\begin{array}{l}\text { Impairment level when last seen* (Oxford and Scotland } \\
\text { only) }\end{array}$ & $n=122$ & $n=38$ & \\
\hline Normal or impairment without disability & $70(60)$ & $18(55)$ & 0.62 \\
\hline Mild disability & $31(26)$ & $8(24)$ & \\
\hline Moderate to severe disability & $16(14)$ & $7(21)$ & \\
\hline
\end{tabular}

but could walk independently with aids. The remaining four teenagers had very low vision and used low vision aids.

Questionnaires were completed by 169 of 179 ELGA teenagers and by 174 of the 179 parents. Of the 29 teenagers in special school, 22 returned a completed questionnaire. Six had completed the questionnaire entirely on their own, 11 with help, and for five the questionnaire was completed by someone else without help from the teenager. All 29 parents of teenagers in special schools returned a questionnaire. All 108 control teenagers completed questionnaires, as did 100 of their parents. Occasionally, two control teenagers "linked" to one index ELGA teenager responded. As no matched analysis was planned, both were included in the control group.

Because of the design of the study, questionnaires for control teenagers were completed later than the ELGA group. The mean (SD) age of completion of the ELGA teenager questionnaire was $15.6(0.56)$ years and for the control teenagers was

\begin{tabular}{|c|c|c|c|c|c|}
\hline & $\begin{array}{l}\text { All ELGA teenagers } \\
(n=174)\end{array}$ & $\begin{array}{l}\text { ELGA teenagers in } \\
\text { special schools } \\
(n=29)\end{array}$ & $\begin{array}{l}\text { ELGA teenagers in } \\
\text { mainstream } \\
\text { schools }(n=145)\end{array}$ & $\begin{array}{l}\text { Control group } \\
(n=100)\end{array}$ & $\begin{array}{l}\text { p Value for } \\
\text { difference between } \\
\text { mainstream ELGA } \\
\text { and controls }\end{array}$ \\
\hline \multicolumn{6}{|l|}{ Sex } \\
\hline Male & $80(46)$ & $12(41)$ & $68(47)$ & $41(41)$ & \multirow{2}{*}{0.43} \\
\hline Female & $94(54)$ & $17(59)$ & 77 (53) & $59(59)$ & \\
\hline \multicolumn{6}{|l|}{ Responding parent } \\
\hline with partner & $138(79)$ & $18(62)$ & $120(83)$ & $87(87)$ & \multirow[t]{2}{*}{0.47} \\
\hline without partner & $35(20)$ & $11(38)$ & $24(17)$ & $13(13)$ & \\
\hline No siblings & $24(14)$ & $2(7)$ & $22(15)$ & $6(6)$ & 0.039 \\
\hline \multicolumn{6}{|l|}{ Social class } \\
\hline Professional/semiprofessional & $45(26)$ & $6(21)$ & $39(27)$ & 37 (37) & \multirow[t]{5}{*}{0.083} \\
\hline Skilled & $67(39)$ & $8(28)$ & $59(41)$ & $44(44)$ & \\
\hline Semiskilled/unskilled & $21(12)$ & $3(10)$ & $18(12)$ & 11 (11) & \\
\hline Armed forces & $2(1)$ & 0 & $2(1)$ & $1(1)$ & \\
\hline No paid employment & $39(22)$ & $12(41)$ & 27 (19) & 7 (7) & \\
\hline \multicolumn{6}{|l|}{ Maternal education } \\
\hline No qualifications & $61(37)$ & $12(44)$ & $49(35)$ & $30(30)$ & \multirow[t]{3}{*}{0.28} \\
\hline School qualifications & $83(50)$ & $15(56)$ & $68(49)$ & $46(46)$ & \\
\hline University degree & $22(13)$ & 0 & $22(16)$ & $24(24)$ & \\
\hline
\end{tabular}

Values are number (percentages) of teenagers Note: responses to some questions were occasionally missing. Percentages are based on the number of valid responses.

ELGA, Extremely low gestational age. 
Table 3 Health and other conditions, as reported by parents, among all ELGA teenagers and a comparison between mainstream ELGA and control teenagers

\begin{tabular}{|c|c|c|c|c|c|c|}
\hline & \multirow[b]{2}{*}{$\begin{array}{l}\text { All ELGA teenagers } \\
(n=174)\end{array}$} & \multirow{2}{*}{$\begin{array}{l}\text { ELGA teenagers in } \\
\text { special schools } \\
(n=29)\end{array}$} & \multirow{2}{*}{$\begin{array}{l}\text { ELGA teenagers in } \\
\text { mainstream } \\
\text { schools }(n=145)\end{array}$} & \multirow[b]{2}{*}{$\begin{array}{l}\text { Control group } \\
(n=100)\end{array}$} & \multicolumn{2}{|c|}{ Mainstream ELGA v controls } \\
\hline & & & & & $\begin{array}{l}\text { Difference in \% } \\
(95 \% \mathrm{Cl})\end{array}$ & $\mathrm{p}$ Value \\
\hline No health problems & $40(23)$ & $0(0)$ & $40(28)$ & $49(49)$ & $-21(-34$ to -9$)$ & $<0.001$ \\
\hline Asthma & $40(23)$ & $3(10)$ & $37(26)$ & 19 (19) & $7(-4$ to 17$)$ & 0.28 \\
\hline Vision problems & $55(32)$ & $17(59)$ & $38(26)$ & $14(14)$ & 12 (2 to 22$)$ & 0.026 \\
\hline Learning difficulties & $55(32)$ & $25(86)$ & $30(21)$ & $3(3)$ & 18 (10 to 25$)$ & $<0.0001$ \\
\hline Behavioural & $52(30)$ & 17 (59) & $35(24)$ & 7 (7) & 17 (9 to 26$)$ & $<0.001$ \\
\hline Cerebral palsy & $20(11)$ & $11(38)$ & $9(6)$ & $0(0)$ & $6(2$ to 10$)$ & 0.012 \\
\hline Hearing problems & $21(12)$ & $9(31)$ & $12(8)$ & $6(6)$ & $2(-4$ to 9$)$ & 0.62 \\
\hline Epilepsy & $14(8)$ & $10(34)$ & $4(3)$ & $0(0)$ & $3(-3$ to 9$)$ & 0.15 \\
\hline
\end{tabular}

Values are numbers (percentages) of teenagers.

ELGA, Extremely low gestational age; $\mathrm{Cl}$, confidence interval.

$16.0(0.46)$ years. Of the 174 questionnaires completed by ELGA parents, 148 were completed by mothers, 16 by fathers, and 10 by another caregiver. Among the 100 questionnaires completed by control parents, 96 were completed by mothers, one by a father, and three by another caregiver.

General practitioners provided information on 167 ELGA teenagers and 88 controls.

Completed questionnaires were available from teachers for 120 ELGA mainstream teenagers and 92 controls.

For 43 teenagers who were identified from the parent and teenager questionnaires as having special needs or using specialist services, additional information was available from paediatricians and community services.

\section{Sociodemographic factors}

Family structure was similar for ELGA teenagers in mainstream school (mainstream ELGA teenagers) and controls, although the former were more likely to have no siblings (table 2). There was no clear difference in social class distribution. The level of maternal education attained was similar in mothers of mainstream ELGA teenagers and controls.

\section{Health and other conditions reported by parents}

Parents reported that 28\% (40/145) of mainstream ELGA children had no health problems, compared with 49\% (49/100) of control children. None of the parents with children in special schools reported "no health problems" (table 3). In general, there was a higher proportion of health problems among the special school children compared with the mainstream ELGA teenagers, who in turn had a higher incidence of reported problems than the controls. The most common conditions in teenagers reported by parents were asthma, vision problems, learning difficulties, and behavioural problems. All except asthma occurred more commonly in mainstream ELGA teenagers than controls (table 3 ).

The impact of this increased burden of disease in the ELGA teenagers was reflected in the parents' responses to questions from the Child Health Questionnaire. The mean scores for overall global health and physical functioning were lower in the mainstream ELGA group than the controls and even lower in the special school group (table 4). Even among the mainstream ELGA teenagers, their parents reported that the teenagers' day to day lives were more likely to be limited by their physical health, both in terms of the kind of activities they could do and the amount of time they could spend on them compared with the control group.

In turn, the impact on the parents of ELGA teenagers was considerable (table 5). This was much more apparent in parents of children in special schools than in those in mainstream school. The parents of ELGA teenagers also reported negative effects of their teenager's health and behaviour on family life and functioning. Although among the control population, a few teenagers do limit family activities, and the health and behaviour of a quarter are reported by parents to be a source of tension and conflict, all aspects of family disruption were reported more often by ELGA parents. The mean

Table 4 Teenagers' health and activities reported by parents: based on child health questionnaire

\begin{tabular}{|c|c|c|c|c|c|c|}
\hline & \multirow[b]{2}{*}{$\begin{array}{l}\text { All ELGA } \\
\text { teenagers } \\
(n=174)\end{array}$} & \multirow[b]{2}{*}{$\begin{array}{l}\text { ELGA teenagers in } \\
\text { special schools } \\
(\mathrm{n}=29)\end{array}$} & \multirow[b]{2}{*}{$\begin{array}{l}\text { ELGA teenagers in } \\
\text { mainstream } \\
\text { schools }(n=145)\end{array}$} & \multirow[b]{2}{*}{$\begin{array}{l}\text { Control group } \\
(n=100)\end{array}$} & \multicolumn{2}{|l|}{ Mainstream $v$ control } \\
\hline & & & & & $\begin{array}{l}\text { Difference in means } \\
(95 \% \mathrm{Cl})\end{array}$ & $\mathrm{p}$ Value \\
\hline \multicolumn{7}{|l|}{ Global health } \\
\hline Mean (SD) & $82.8(20.4)$ & $71.6(24.7)$ & $85.1(18.7)$ & $89.4(13.0)$ & $-4.3(-8.3$ to -0.3$)$ & 0.035 \\
\hline \multicolumn{7}{|c|}{ Physical functioning } \\
\hline Mean (SD) & $83.7(30.3)$ & $51.4(38.1)$ & $90.0(24.2)$ & $99.0(4.8)$ & $-9.0(-13.1$ to -4.9$)$ & $<0.001$ \\
\hline \multicolumn{7}{|c|}{ Limited in kind of school work or activities with friends No $(\%)$} \\
\hline A lot & $17 \quad(10)$ & $9 \quad(33)$ & $8 \quad(6)$ & $0 \quad(0)$ & & \multirow[t]{4}{*}{0.014} \\
\hline Quite a bit & 12 (7) & $4 \quad(15)$ & 8 (6) & 1 (1) & & \\
\hline Slightly & $8 \quad(5)$ & $5 \quad(19)$ & $3(2)$ & $4 \quad(4)$ & & \\
\hline Not at all & $134 \quad(78)$ & $9 \quad(33)$ & 125 (87) & $94 \quad(95)$ & & \\
\hline \multicolumn{7}{|c|}{ Limited in amount of time spent on school work or activities with friends No (\%) } \\
\hline A lot & $14 \quad(8)$ & $7 \quad(27)$ & $7 \quad(5)$ & 0 & & \multirow{4}{*}{0.009} \\
\hline Quite a bit & $8 \quad(5)$ & 2 (8) & $6 \quad(4)$ & 0 & & \\
\hline Slightly & $9 \quad(5)$ & $7 \quad(27)$ & 2 (1) & $4 \quad(4)$ & & \\
\hline Not at all & $139 \quad(82)$ & $10 \quad(38)$ & 129 (90) & $95 \quad(96)$ & & \\
\hline \multicolumn{7}{|c|}{ Limitations because of physical health } \\
\hline Mean (SD) & $85.1(31.5)$ & $53.7(41.2)$ & $91.0(25.5)$ & $98.3(6.9)$ & $-7.3(-11.7$ to -2.9$)$ & 0.001 \\
\hline
\end{tabular}

Note: Responses to some questions were occasionally missing. Percentages are based on the number of valid responses. Responses about limitations because of physical health missing for one parent in ELGA group and one in control group. ELGA, Extremely low gestational age; Cl, confidence interval. 
Table 5 Impact on parents and family reported by parents: based on child health questionnaire

\begin{tabular}{|c|c|c|c|c|c|}
\hline & $\begin{array}{l}\text { All ELGA } \\
\text { teenagers } \\
(n=174)\end{array}$ & $\begin{array}{l}\text { ELGA teenagers } \\
\text { in special schools } \\
(n=29)\end{array}$ & $\begin{array}{l}\text { ELGA teenagers } \\
\text { in mainstream } \\
\text { school }(n=145)\end{array}$ & $\begin{array}{l}\text { Control group } \\
(n=100)\end{array}$ & $\begin{array}{l}\text { p Value for } \\
\text { difference } \\
\text { between } \\
\text { mainstream ELGA } \\
\text { and controls }\end{array}$ \\
\hline \multicolumn{6}{|l|}{$\begin{array}{l}\text { Time for parent's own personal needs limited by: } \\
\text { teenager's physical health }\end{array}$} \\
\hline A lot or quite a bit & $17 \quad(10)$ & $10 \quad(37)$ & $7 \quad(5)$ & $1 \quad(1)$ & 0.28 \\
\hline Slightly & 11 (6) & 5 (19) & $6 \quad(4)$ & $4 \quad(4)$ & \\
\hline Not at all & 144 & 12 (44) & 132 (91) & $95 \quad(95)$ & \\
\hline \multicolumn{6}{|l|}{ teenager's emotional wellbeing } \\
\hline A lot or quite a bit & $26 \quad(15)$ & $13 \quad(46)$ & 13191 & $2 \quad(2)$ & 0.079 \\
\hline Slightly & 22 (13) & $9 \quad(32)$ & 13 (9) & 11 (11) & \\
\hline Not at all & $125 \quad(72)$ & $6 \quad(12)$ & 119 (82) & $86 \quad(87)$ & \\
\hline \multicolumn{6}{|l|}{ teenager's attention/learning problems } \\
\hline A lot or quite a bit & 22 (13) & $15 \quad(56)$ & $7 \quad(5)$ & 0 & 0.076 \\
\hline Slightly & $18 \quad(10)$ & $10 \quad(37)$ & $816)$ & $4 \quad(4)$ & \\
\hline Not at all & 132 (77) & $2(7)$ & $130 \quad(90)$ & $95 \quad(96)$ & \\
\hline $\begin{array}{l}\text { Overall time impact on parent, mean (SD)* } \\
\text { Teenager's health or behaviour has: } \\
\text { limited family activities }\end{array}$ & $86.2(25.6)$ & $51.0(32.9)$ & $93.0(17.2)$ & $97.1(9.1)$ & 0.016 \\
\hline Fairly or very often & 25 (14) & $13 \quad(45)$ & 12 (8) & $1 \quad(1)$ & 0.048 \\
\hline Sometimes & $21 \quad(12)$ & $9 \quad(31)$ & 12 (8) & 9 (9) & \\
\hline Never or nearly never & $128 \quad(74)$ & $7 \quad(24)$ & $121 \quad(83)$ & $89(90)$ & \\
\hline \multicolumn{6}{|l|}{ interrupted everyday family activities } \\
\hline Fairly or very often & $19 \quad(11)$ & $11 \quad(38)$ & $8 \quad(6)$ & $3 \quad(3)$ & 0.036 \\
\hline Sometimes & 23 (13) & $7 \quad(24)$ & $16 \quad$ (11) & $3 \quad(3)$ & \\
\hline Never or nearly never & $132 \quad(76)$ & $11 \quad(38)$ & 121 & 94 (94) & \\
\hline \multicolumn{6}{|l|}{ been a source of tension or conflict } \\
\hline Fairly or very often & $28 \quad(16)$ & $10 \quad(34)$ & $18 \quad(12)$ & $4 \quad(4)$ & 0.082 \\
\hline Sometimes & $42 \quad(24)$ & $11 \quad(38)$ & $31 \quad(21)$ & $22(22)$ & \\
\hline Never or nearly never & $104(60)$ & $8 \quad(28)$ & $96 \quad(66)$ & $74 \quad(74)$ & \\
\hline \multicolumn{6}{|l|}{ brought you closer as a family } \\
\hline Fairly or very often & $35 \quad(21)$ & $14 \quad(52)$ & $21 \quad(15)$ & $21 \quad(21)$ & 0.25 \\
\hline Sometimes & $44 \quad(26)$ & $9 \quad(33)$ & $35 \quad(24)$ & $28 \quad(28)$ & \\
\hline \multirow{2}{*}{\multicolumn{6}{|c|}{ caused change of plans }} \\
\hline & & & & & \\
\hline Fairly or very offen & 16 (9) & $9 \quad(32)$ & $7 \quad(5)$ & $1 \quad(1)$ & 0.13 \\
\hline Sometimes & 28 (16) & $12 \quad(43)$ & $16 \quad$ (11) & 7 (7) & \\
\hline Never or nearly never & $129 \quad(75)$ & $7 \quad(25)$ & 122 & 92 (92) & \\
\hline $\begin{array}{l}\text { Overall family activities, mean (SD) } \dagger \\
\text { Family "ability to get along" }\end{array}$ & $78.6(28.6)$ & $43.9(30.3)$ & $85.6(22.6)$ & 90.2 (14.3) & 0.052 \\
\hline Excellent or very good & $101 \quad(58)$ & $15 \quad(52)$ & $86 \quad(59)$ & $66 \quad(66)$ & 0.004 \\
\hline Good & 42 (24) & $11 \quad(38)$ & $31 \quad(21)$ & $30 \quad(30)$ & \\
\hline Fair or poor & 31 (18) & $3 \quad(10)$ & 28 (19) & 4 (4) & \\
\hline Family cohesion, mean (SD)‡ & $71.4(24.9)$ & $72.4(21.1)$ & $71.2(25.7)$ & $78.2(17.5)$ & 0.012 \\
\hline
\end{tabular}

of the measure of overall family cohesion was significantly lower in ELGA parents than controls, although no lower among the special school ELGA teenagers than the mainstream group.

\section{Health and other conditions self reported by teenagers} Teenagers were asked a series of 11 questions about how they felt about their health (taken from the Child Health Questionnaire). In these they were asked to respond to questions about past and present health and their views on future health. The responses can be summated to produce a single score of "health perception" (maximum score $=100$ ). The mean (SD) score for the mainstream ELGA group (74.1 (17.9)) did not differ from the mean score for the control group (73.5 (16.3)) or the special school group (69.7 (22.8)). Two thirds of both ELGA groups and the control group considered they were in excellent health (mainstream ELGA 93/144 (65\%), special school ELGA 13/21 (62\%), controls $74 / 108(69 \%))$. Twice as many mainstream ELGA teenagers $(14 / 147 ; 10 \%)$ as control teenagers $(5 / 108 ; 5 \%)$ considered they were less healthy than others (difference 5\%, 95\% CI -1 to 11$)$, and $30 \%(6 / 20)$ of ELGA children in special schools judged themselves to be less healthy than others.

When asked about specific health problems, such as headache, stomach ache, backache, sleep problems, and "feeling low", these were reported as often (or more often, in the case of backache and feeling low) by controls as by mainstream ELGA teenagers.

There appeared to be no delay in the onset of periods in ELGA girls; the age of menarche was similar in both the ELGA groups (mean (SD) age for mainstream ELGA 12.3 (1.2), special school ELGA 12.1 (1.6), and controls 12.7 (1.3) years). All but one of the ELGA girls and all of the control group had reached menarche by the age of 16 years. The mean age at which the voice broke was similar in the three groups: mainstream ELGA 13.5 (1.1), special school ELGA 12.8 (0.98), and control 13.6 (1.2) years. The voice had not yet broken in 10 boys (seven ELGA and three control).

\section{Use of medicines}

Medicines were widely used by both ELGA and control teenagers. Similar proportions of mainstream ELGA (58/145: $40 \%$ ), special school ELGA (10/22: $45 \%$ ), and control teenagers 
Table 6 School performance based on teachers' reports

\begin{tabular}{|c|c|c|c|}
\hline & $\begin{array}{l}\text { ELGA teenagers } \\
\text { in mainstream } \\
\text { school }(n=120)\end{array}$ & $\begin{array}{l}\text { Control group } \\
(n=92)\end{array}$ & $\begin{array}{l}\text { Difference in } \\
\text { proportions or means } \\
(95 \% \mathrm{CI})\end{array}$ \\
\hline Ever had learning support, No (\%) & $38(32)$ & $4(4)$ & 27 (18 to 37$)$ \\
\hline Statement of needs, No (\%) & $23(19)$ & $2(2)$ & 17 (9 to 25$)$ \\
\hline \multicolumn{4}{|l|}{ Assessment of ability, mean (SD) } \\
\hline General ability & $14.9(7.4)$ & $21.8(5.9)$ & $6.9(5.0$ to 8.8$)$ \\
\hline Reading & $16.3(7.8)$ & $22.5(5.6)$ & $6.2(4.3$ to 8.1$)$ \\
\hline Handwriting* & $15.5(7.4)$ & $22.6(5.5)$ & $7.0(5.2$ to 8.9$)$ \\
\hline Computing and keyboard & $15.1(7.4)$ & $20.7(6.2)$ & $5.6(3.7$ to 7.5$)$ \\
\hline Spelling & $14.2(7.6)$ & $20.9(6.5)$ & $6.7(4.8$ to 8.7$)$ \\
\hline Mathematical skills & $13.8(7.9)$ & $20.7(7.0)$ & $6.9(4.8$ to 9.0$)$ \\
\hline Creative writing & $15.2(7.8)$ & $20.9(6.5)$ & 5.7 (3.7 to 7.7$)$ \\
\hline Independent learning & $15.0(7.8)$ & $21.2(6.8)$ & $6.2(4.2$ to 8.2$)$ \\
\hline Concentration & $16.0(8.0)$ & $21.0(6.8)$ & $5.0(3.0$ to 7.0$)$ \\
\hline Cooperativeness & $21.4(7.1)$ & $23.5(5.6)$ & $2.1 \quad(0.3$ to 3.9$)$ \\
\hline Individual sport* & $14.1(7.3)$ & $18.8(6.5)$ & $4.7(2.7$ to 6.6$)$ \\
\hline Team sport* & $13.7(7.7)$ & $19.1(6.8)$ & $5.4(3.3$ to 7.4$)$ \\
\hline
\end{tabular}

(42/107: 39\%) had had no medicines in the previous four weeks. The most often used medicines were for headache (mainstream ELGA 53/145 (37\%) and control 40/107 (37\%)) and for colds and sore throat (mainstream ELGA 30/145 (21\%) and controls 20/107 (19\%)). Teenagers from special schools used these less often (headache, 2/22 (9\%) and colds and sore throat, $3 / 22(14 \%))$.

\section{Use of health service}

Two thirds of the mainstream ELGA teenagers (89/141: 63\%) and the controls (58/88: 65.9\%) had visited their general practitioner within the previous year. This compared with $77 \%$ (20/26) of the ELGA teenagers in special schools. Similar proportions of mainstream ELGA $(21 / 141 ; 15 \%)$ and control teenagers $(13 / 88 ; 15 \%)$ had been admitted to hospital in the previous six years. In contrast, 39\% (10/26) of teenagers in special schools had been admitted to hospital in the same time period.

\section{Smoking, alcohol, and "recreational" drugs}

About $10 \%$ of both mainstream ELGA (15/147; 10\%) and control $(10 / 108 ; 9 \%)$ teenagers smoked every day. None of the ELGA teenagers in special schools reported having smoked. Among mainstream ELGA teenagers, 41\% (60/146) said that they never drank alcohol compared with $20 \%$ (22/108) of control teenagers (difference $21 \%, 95 \%$ CI 10 to 32 ). In contrast, $82 \%(18 / 22)$ of ELGA teenagers in special schools reported that they never drank alcohol. Most (92\%; 132/144) ELGA teenagers in mainstream schools said that they had never used cannabis compared with 76\% (82/108) of control teenagers. A small number were regular or occasional cannabis users, two in the mainstream ELGA group and eight in the control group. The use of other drugs including solvents, speed, ecstasy, LSD, and cocaine were reported in both mainstream ELGA and control groups, but very rarely.

\section{School performance}

Among those in mainstream school, the ELGA group needed far more learning support in all areas than the control group (table 6). A quarter of mainstream ELGA children (36/145) had seen an educational psychologist for assessment compared with 3/100 controls (difference 22\% (95\% CI 14 to 30). The mean scores derived from the teachers' rating of ability were significantly lower in all areas for the ELGA teenagers than the controls. Similarly, the proportion of ELGA children with a below average score in overall ability was much higher than among controls (17\% compared with $2 \%$; difference $15 \%$, $95 \%$ CI 7 to 22 ).
These differences in ability were also apparent from the results of the SATS (Key Stage 3), which were available for teenagers attending English schools, and the Standard Grade assessments, available for teenagers attending Scottish schools. For example, in English SATS, 24/65 (37\%) of ELGA children achieved grade 5 or above compared with 24/41 (59\%) controls (difference $-22 \%, 95 \%$ CI -40 to -3 ); in maths the corresponding proportions were $26 / 65(40 \%)$ and $26 / 41$ (63\%) (difference $-23 \%, 95 \%$ CI -42 to -4 ). In the Standard Grade assessments, presentation for credit in English was achieved by $28 / 55$ (51\%) of ELGA children compared with $40 / 51$ ( $78 \%$ ) of controls; difference $-28 \%, 95 \%$ CI -45 to -10$)$. In maths the comparative proportions were ELGA 14/55 (25\%) and controls $32 / 51$ (63\%), (difference $-37 \%, 95 \%$ CI -55 to $-20)$.

\section{Attitude of teenagers to school}

Despite their academic difficulties, three quarters of mainstream ELGA teenagers (74\%: 109/147) said that they liked rather than disliked school, compared with 89/108 (82\%) of control teenagers (table 7). They were aware, however, of their difficulties at school. A higher proportion of mainstream ELGA teenagers than controls reported difficulties with concentration, and slightly more mainstream ELGA teenagers than controls felt that their parents did not expect enough of them at school. Although overall absences from school did not differ between mainstream ELGA teenagers and controls, a small number of ELGA teenagers were missing a lot of school because of illness or hospital appointments. Bullying was common in both mainstream ELGA and control teenagers but did not differ between the two groups; in a few (four ELGA and three controls) this had continued for over a year.

\section{Plans for the future}

A lower proportion of mainstream ELGA teenagers than controls were planning to stay on at school to do higher academic or vocational qualifications (ELGA 103/147 (70\%), controls 90/108 (83\%); difference $-13 \%, 95 \%$ CI -24 to -3$)$. Of those leaving school, more mainstream ELGA teenagers than controls were planning some type of apprenticeship training or employment course (ELGA 29/44 (66\%), controls 5/18 $(28 \%)$ ), and a few in each group (mainstream ELGA five, control nine) were leaving to get a job. A third of ELGA teenagers in special schools $(10 / 28 ; 38 \%)$ planned to do higher academic or vocational qualifications, and two apprenticeship training. A small number (10/147 mainstream ELGA teenagers and $4 / 108$ controls) said that they did not know what they would do next. However, half (14/28) the ELGA teenagers in special 
Table 7 Teenagers' attitudes to school

\begin{tabular}{|c|c|c|c|c|c|c|}
\hline \multirow[b]{2}{*}{ Likes school } & \multicolumn{2}{|c|}{$\begin{array}{l}\text { ELGA teenagers } \\
\text { in mainstream } \\
\text { school }(n=147)\end{array}$} & \multicolumn{2}{|c|}{$\begin{array}{l}\text { Control group } \\
(n=108)\end{array}$} & $\begin{array}{l}\text { Difference in } \\
\text { proportions or } \\
\text { means }(95 \% \mathrm{CI})\end{array}$ & \multirow{2}{*}{$\begin{array}{l}\begin{array}{l}\text { p Value for } \\
\text { difference } \\
\text { between } \\
\text { groups }\end{array} \\
0.13\end{array}$} \\
\hline & 109 & (74) & 89 & (82) & $-8 \quad(-18$ to 2$)$ & \\
\hline \multicolumn{7}{|l|}{ Difficult to concentrate at school } \\
\hline All or most of the time & 15 & (10) & 1 & (1) & & 0.005 \\
\hline Sometimes/occasionally & 78 & (53) & 71 & (66) & & \\
\hline Never & 53 & (36) & 36 & (33) & & \\
\hline Feels pressured by school work & 40 & (27) & 26 & (24) & $3 \quad(-8$ to 14$)$ & 0.66 \\
\hline "Parents do not expect enough of me at school" & 56 & (39) & 28 & (26) & 13 (1 to 24$)$ & 0.042 \\
\hline "Teachers do not expect enough of me at school" & 41 & (29) & 25 & (24) & $5 \quad(-6$ to 16$)$ & 0.39 \\
\hline \multicolumn{7}{|l|}{ Misses school because not well } \\
\hline All or most of the time & 6 & (4) & 4 & (4) & & 0.78 \\
\hline Sometimes/occasionally & 91 & (62) & 72 & (67) & & \\
\hline Never & 49 & (34) & 32 & (30) & & \\
\hline \multicolumn{7}{|l|}{ Misses school because of appointments } \\
\hline All or most of the time & 11 & (8) & 2 & (2) & & 0.05 \\
\hline Sometimes/occasionally & 60 & (41) & 38 & (35) & & \\
\hline Never & 75 & (51) & 68 & (63) & & \\
\hline Absence from school (number of days over 12 months), mean (SD) & 12.0 & $(13.8)$ & 11.8 & 3 (16.9) & $0.2(-3.6$ to 4.0$)$ & 0.92 \\
\hline Bullied in school & 46 & (32) & 34 & (32) & $0 \quad(-11$ to 12$)$ & 0.98 \\
\hline Bullied out of school & 20 & (14) & 16 & (15) & $-1 \quad(-10$ to 8$)$ & 0.93 \\
\hline
\end{tabular}

school either did not know what they would do after leaving school or did not respond to the question.

\section{DISCUSSION}

In our study of teenagers born very preterm in the early 1980 s and alive at age 16 years, one in six had severe motor, sensory, intellectual, or behavioural difficulties and were in a special school. Most of the survivors, however, are in mainstream school, are in good health, are coping well with academic challenges, and have a positive view of the future. Despite this, as a group and in the view of the parents, those in mainstream school have more health problems and are limited in their physical and school activities compared with a group of classroom controls. In the view of their teachers and in their school test scores, they have a lower educational attainment. The teenagers themselves, on the other hand, do not in general appear to differ to any great extent from their classroom peers in their perception of their own health, use of medications, or views and experience of school.

Many of the earlier studies of the later health and abilities of babies born very preterm have focused on the outcome of the ELGA group as reported by caregivers or teachers without ascertaining the views of the children themselves and sometimes without a comparison group.

The issue of the selection of appropriate comparison groups has not been fully resolved in most studies and depends to a certain extent on the questions being posed. We were anxious to investigate the longer term impact of being born at extremely low gestational age on functioning in young adult life among peers. In some numerically small psychological studies, sibling comparisons have been used, but these are generally unsatisfactory because it is difficult to compare children of differing maturity in a continuously changing developmental situation. The most commonly used method is the one we have used of selecting a comparison group from children who have had the same educational experience as the index child. Nevertheless we were anxious to include the whole cohort of survivors in as far as they were able to contribute to the study. Selecting a comparison group from a special school population is not an option, given that the concept of an age based class is not applicable as classes are based on the ability to participate in a particular activity. Although it may be cumbersome, we have therefore presented the available data on all the children in the cohort, while highlighting the comparison with the control group in mainstream school.

A particular aim of this study was to use a simple relatively inexpensive way of assessing outcome with a focus on the views of both parents and teenagers of their functional level and integration into school, family, and social life, rather than focusing on diagnosis and impairment. Although psychometric testing and physical examination may be useful in understanding the causes and pathophysiology of the specific deficits seen in children born very preterm, we were more concerned with the way in which such deficits impinge on function as these teenagers embark on adult life.

By using self completed anonymised questionnaires, we hoped that teenagers and parents would give us an honest picture of their health and attitudes, which might be more difficult to obtain with a face to face approach. On the other hand, the response rate from postal questionnaires is likely to be lower than from a direct approach. ${ }^{19}$ In this study, in one of the three centres, families were visited to carry out a more detailed assessment, as part of another study. The follow up rate in this centre was $98 \%$ compared with $76 \%$ in the other two centres, giving an overall rate of $82 \%$. As questionnaires were completed before the visit to the family, we do not think this different approach in one centre invalidates pooling data from the three centres. Personal contact by a health professional known to the family, provided that it allows scope for the parent or teenager to refuse participation, is clearly valuable when approaching families in these types of study.

There is always a concern that the outcome of the children not seen or assessed will differ from those seen. ${ }^{20}$ We had the advantage of previous assessments at earlier ages for almost all the ELGA teenagers from two of the three areas. For these teenagers, those who did not respond had similar levels of disability to those who did respond. However, the nonresponders included a higher proportion of children without previous assessment than the responders. We were aware that there are some difficult family situations and social problems among some of these long term "non-responders", and this needs to be borne in mind when interpreting the group findings. There was also a tendency to a lower social class among the non-responders. As school performance is influenced by social class, the ELGA group who responded may have had a better level of school performance than the non-responders. 
It was difficult to assess the extent of any selection bias among the age matched control population. Although the staff in many schools were very helpful in identifying controls, some were reluctant to participate. In addition, there may have been an element of self selection among the teenagers themselves. It is plausible that it would be the more articulate, brighter teenagers who would be more likely to respond to a questionnaire, and this would increase apparent differences in academic performance between ELGA and control teenagers. On the other hand, those with problems or issues that they wanted to express may be more likely to respond, and this may reduce differences between ELGA and control groups. There is some suggestion of a more favourable social class distribution and a higher level of maternal education in the controls than the ELGA group, although this did not reach significance at the $5 \%$ level. Although on the analogue scales used by teachers, the control teenagers tended to score above average level, the proportion who attained level 5 or above on SATS Key Stage 3 was similar to the published national figures. Hence, $59 \%$ of control teenagers attained level 5 or more compared with $65 \%$ on the national average figures for $1998,{ }^{21}$ and $63 \%$ attained level 5 or more in maths compared with the national figure of 59\%. In addition, the mean scores for controls on the questions from the Child Health Questionnaire are comparable to those of the normal age equivalent population. ${ }^{18}$

Studies of the outcome in school years of children born very preterm have tended to focus on academic performance, cognitive function, and behaviour. There has been less focus on physical ill health and its effects on the children and their families. Although in early years there is a high rate of readmission to hospital, ${ }^{22}$ particularly among those with chronic lung disease ${ }^{23}{ }^{24}$ health effects tend to lessen as the years go by. ${ }^{25} 26$ We found that similar proportions of mainstream ELGA and control teenagers visited their general practitioner and were readmitted to hospital, although more of those in special schools had been admitted. On the basis of parent reports, however, teenagers born very preterm still tend to have more health problems that limit day to day activities, both at school and with friends, and that also impact on parents and the family.

The impact of having a very preterm baby is present from early days and may influence whether parents have further children. The tendency for children born very preterm to have no siblings has been described previously ${ }^{27}$ and is found in this study population. It is possible that parents of preterm children who have a severe disability would be less likely to have further children than parents of non-disabled children, but we found no evidence of this. There is also a concern that having a preterm baby and the associated anxiety can place excessive stress on marriage relationships, and we found that over a third of the teenagers in special schools were in a single parent family. Continuing adverse impact on parents and families appears to arise not only from continuing health problems, but also from emotional and behavioural difficulties. Using a comparison group has allowed us to explore the impact of these aspects on the families over and above the normal turmoil of teenage behaviour. Although there are clearly a few ELGA teenagers who severely limit family activities and cohesion, most appear to be as well socially integrated as their classroom peers. It remains to be seen if any of these early difficulties have an impact on their own parenting abilities. A more detailed analysis of the differences between ELGA and control teenagers in the prevalence of emotional and behavioural difficulties is the subject of another paper.

There is now widespread recognition that in early school years, children who were born very preterm or with a very low birth weight have poorer school performance, difficulties in cognitive and visuospatial areas, and an increased likelihood of the need for special educational support. ${ }^{378}$ More recently, it has become clear that these difficulties remain into later school years and adolescence, ${ }^{5628}$ and indeed the academic gap may widen. ${ }^{5}$ Although all areas of learning can be involved, particular problems in mathematical skills (both on objective tests and as perceived by the teenagers themselves) and complex conceptual tasks, have been identified, ${ }^{56}$ together with poor fine motor control..$^{30}$ These areas of poor performance appear to have been confirmed in this study. It has been suggested that these difficulties may result in deficits in "executive planning", ${ }^{31}$ giving rise to difficulties when faced with academic and day to day tasks and which may have implications in future employment.

In the shorter term, such deficits result in a need for learning support throughout the school career, drawing heavily on educational resources. ${ }^{42}$ Educational authorities differ in their policies of integration. This not only has budgetary implications, but differing integration policies for children with disabilities can lead to some problems in comparing studies where populations are defined by school placement. There are also difficulties in using the proportion of the population who attend special schools as an index of "good outcome" for low birthweight, low gestational age children. By presenting the results in full, we hope to have overcome some of these problems. Although within the total cohort whose present status was known, 16\% (29/179) were known to be at a special school, there were a further 10 teenagers with severe physical disability in mainstream school and these have been included in our comparison analyses. We recognise that they have had an important impact on questions relating to physical function and may have widened differences between ELGA and control groups in some domains.

A further aspect of this study which has rarely been used previously was the use of the results of National Curriculum tests and standard Scottish tests to compare the school performance of the two groups. Although there is considerable criticism of several aspects of these systems, they discriminated remarkably well between the abilities of the ELGA and control teenagers. This was also the finding in an earlier study in which Key Stage 1 results were used as one way of measuring school performance in a large study of seven year old children of differing birth weights. ${ }^{33}$ This may be a useful approach for ascertaining outcomes in large multicentre trials or studies where follow up may otherwise be very time consuming and expensive. Combining information from child health systems and the educational services could, if fully implemented, be a powerful way of monitoring the impact of increasing survival of the very immature infant.

One of the most interesting findings in this study was the apparent difference between ELGA parents and teenagers in their perception of illness and abilities, an observation also made by Saigal et $a l^{34}$ in their study of babies born with an extremely low birth weight and more recently by Dinesen and Greisen. ${ }^{35}$ These differing perceptions in our study population are being explored and will be reported in a further paper.

In summary, there appears to be a residual morbidity among ELGA teenagers attending mainstream school when compared with classroom peers. Although a number of them have serious academic and health difficulties, most feel they are coping well with school and family life and have a positive view of the future. The optimistic views of the teenagers themselves, however, should not obscure the fact that some of them will need continuing support by health, educational, and social services into adulthood. Quite how they will fare as they meet the challenges of the workplace, establish life long relationships, and themselves adopt a parenting role is not yet known.

\section{ACKNOWLEDGEMENTS}

We thank the teenagers themselves, their parents, teachers, and general practitioners for their cooperation and interest in the study. The study was suggested by Edmund Hey. Members of the ELGA Steering Group were Sarah Arkle, Ursula Bowler, Frances Gardner, Edmund 
Hey, Christine Hockley, Ann Johnson, Michael Jones, Barbara Maughan, Lesley Mutch, Anne Stewart, Unni Wariyar, and Patricia Yudkin. The project was coordinated by Shona Donald in Scotland, Susan Fritz in Newcastle, and overall coordination was by Ursula Bowler in Oxford. Jaideep Singh was involved in data collection in the Northern Region. The project was funded by Action Research. Core funding for the National Perinatal Epidemiology Unit is provided by the Department of Health.

\section{Authors' affiliations}

A Johnson, U Bowler, C Hockley, National Perinatal Epidemiology Unit, Institute of Health Sciences, Old Road, Oxford OX3 7LF, UK P Yudkin, Department of Primary Health Care, University of Oxford, Institute of Health Sciences

U Wariyar, Royal Victoria Infirmary, Newcastle upon Tyne NE 1 4LP, UK F Gardner, Department of Social Policy and Social Work, University of Oxford, Oxford OXI 2ER, UK

L Mutch, Peach Unit, Royal Hospital for Sick Children, University of Glasgow, Glasgow G3 8SJ, Scotland, UK

\section{REFERENCES}

1 Hack M, Fanaroff A. Outcome of extremely low birthweight and gestational age in the 1990s. Early Hum Dev 1999:53:193-218.

2 Wood N, Marlow N, Costeloe K, et al. Neurologic and developmental disability after extremely preterm birth. N Engl J Med 2000;343:378 84.

3 Saigal S, Szatmari $P$, Rosenbaum $P$, et al. Cognitive abilities and school performance of extremely low birthweight children and matched term control children at age 8 years: a regional study. J Pediatr $1991 ; 118: 751-60$

4 Buck G, Msall M, Schisterman E, et al. Extreme prematurity and school outcomes. Paediatr Perinat Epidemiol 2000;14:324-31.

5 Saigal S, Hoult L, Streiner D, et al. School difficulties at adolescence in a regional cohort of children who were extremely low birthweight. Pediatrics 2000;105:325-31

6 Botting N, Powls A, Cooke RWI, et al. Cognitive and educational outcome of very low birthweight children in early adolescence. Dev Med Child Neurol 1998;40:652-60.

7 Hall A, Mcleod A, Counsell C, et al. School attainment, cognitive ability and motor function in a total Scottish very low birthweight population at 8 years: a controlled study. Dev Med Child Neurol 1995;37:1037-50.

8 Horwood LJ, Mogridge N, Darlow B. Cognitive, educational and behavioural outcomes at 7-8 years in a national very low birthweight cohort. Arch Dis Child Fetal Neonatal Ed 1998;79:F12-20.

9 Scottish Low Birthweight Study Group. The Scottish Low Birthweight Study. II. Language attainment, cognitive status and behavioura impairment at 4 years. Arch Dis Child 1992;67:682-6.

10 Botting N, Powls A, Cooke RWI, et al. Attention deficit hyperactivity disorders and other psychiatric outcomes in very low birthweight children at age 12 years. J Child Psychol Psychiatry 1997;38:931-41.

11 Pharoah POD, Stevenson CJ, Cooke RW, et al. Prevalence of behaviour disorders in low birthweight infants. Arch Dis Child 1994;70:271-4.

12 Scottish Low Birthweight Study Group. The Scottish Low Birthweight Study. I. Survival, growth and physical impairment at 4 years. Arch Dis Child 1995;67:675-81.
13 Johnson A, Townshend P, Yudkin P, et al. Functional abilities at age 4 years of children born before 29 weeks gestation. BM 1993;306:1715-18.

14 Wariyar U, Richmond S, Hey E. Pregnancy outcome at 24-31 weeks gestation: mortality. Arch Dis Child 1989:64:670-7.

15 Wariyar U, Richmond S, Hey E. Pregnancy outcome at 24-31 weeks gestation: neonatal survivors. Arch Dis Child 1989;64:678-86.

16 Health Education Authority. Young people's health and lifestyle questionnaire. London: Health Education Authority, 1993.

17 Office of Populations, Censuses and Surveys. Standard occupational classification. London: HMSO, 1990

18 Landgraf JM, Abetz L, Ware JE. The Child Health Questionnaire users manual. 1 st ed. Boston: The Health Institute, New England Medical Center, 1996.

19 Spry VM, Hovell MF, Sallis JG, et al. Recruiting survey respondents to mailed surveys: controlled trials of incentives and prompts. Am J Epidemiol 1989;130:166-72.

20 Tin W, Fritz S, Wariyar U, et al. Outcome of very preterm birth: children reviewed with ease at 2 years differ from those followed up with difficulty. Arch Dis Child Fetal Neonatal Ed 1998;79:F83-7.

21 DFES. National curriculum assessments of 7, 11 and 14 year olds in England 1998. DFES statistics. Statistical bulletin April 1999. London: HMSO, 1999.

22 Mutch L, Ashurst H, Macfarlane AJ. Birthweight and hospital admission before the age of 2 years. Arch Dis Child 1992;67:900-4.

23 McLeod A, Ross P, Mitchell S, et al. Respiratory health in a total very low birth weight cohort and their classroom controls. Arch Dis Child 1996;74:188-94

24 Furman L, Baley J, Borawski-Clark E, et al. Hospitalization as a measure of morbidity among very low birthweight infants with chronic lung disease. J Pediatr 1996;1 28:447-52.

25 Theunissen N, den-Ouden L, Meulman J, et al. Health status development in a cohort of preterm children. J Pediatr 2000;137:534-9.

26 Doyle LW, Cheung MMH, Ford GW, et al. Birthweight $<1501 \mathrm{~g}$ and respiratory health at age 14. Arch Dis Child 2001;84:40-4.

27 Saigal S, Burrows E, Stoskopf BL, et al. Impact of extreme prematurity on families of adolescent children. J Pediatr 2000;137:701-6.

28 Doyle L, Casalaz D for the Victorian Infant Collaborative Study Group. Outcome at 14 years of extremely low birthweight infants: a regional study. Arch Dis Child Fetal Neonatal Ed 2001;85:F159-64.

29 Hack $M$, Flannery DJ, Schluchter $M$, et al. Outcomes in young adulthood for very low birthweight infants. N Engl J Med 2002;346: 149-57.

30 Powls A, Botting N, Cooke RWI, et al. Motor impairment in children, $12-13$ years old with a birthweight of less than $1250 \mathrm{~g}$. Arch Dis Child Fetal Neonatal Ed 1995;73:F62-6.

31 Harvey JM, O'Callaghan M, Mohay $\mathrm{H}$. Executive function of children with extremely low birthweight: a case control study. Dev Med Child Neurol 1999;41:292-7.

32 Lagerstrom $M$, Bremme $K$, Eneroth $P$, et al. Long term development for girls and boys at age 16-18 as related to birthweight and gestational age. Int J Psychophysiol 1994;17:175-98.

33 Middle C, Johnson A, Alderdice F, et al. Birthweight and health and development at the age of 7 years. Child: care, health and development 1996;22:55-71

34 Saigal S, Feeny D, Rosenbaum $P$, et al. Self perceived health status and health-related quality of life of extremely low birthweight infants at adolescence. JAMA 1996;276:453-9.

35 Dinesen S, Greisen G. Quality of life in young adults with very low birthweight. Arch Dis Child Fetal Neonatal Ed 2001;85:F165-9. 